\title{
Coping strategies for stress management and its relationship with the level of obesity and quality of life in bariatric surgery candidates
}

\author{
María Eugenia Terrazas-Romero, ${ }^{1}$ Guadalupe Jazmín Flores-Boyso, ${ }^{1}$ Nallely Teotetl Zenil-Magaña, ${ }^{1}$ \\ Edgar Landa-Ramírez ${ }^{1}$ and Aída Monserrat Reséndiz-Barragán ${ }^{2}$ \\ ${ }^{1}$ Universidad Nacional Autónoma de México, Faculty of Psychology, Health Psychology and Behavioral Medicine Program, Ciudad de México, \\ Mexico; 'Secretaría de Salud, Hospital General "Dr. Manuel Gea González", Sub-directorate of Biomedical Research, Ciudad de México, Mexico
}

\begin{abstract}
Introduction: Stress is a variable that may play an important role in the development of obesity and in the quality of life of patients who are candidates for bariatric surgery, since stress is linked to the consumption of hypercaloric foods, sedentariness and higher incidence of psychological disorders. Objective: To describe the most common types of stress coping strategies in patients who are candidates for bariatric surgery and establish their relationship with body mass index and quality of life perception. Method: One-hundred and one patients with severe obesity who were candidates for bariatric surgery were evaluated by means of the Stress Coping Questionnaire and the Quality of Life and Health Inventory. Results: The most commonly used coping type is action and the most common strategy is focus on problem solving. Five coping strategies were significantly associated with quality of life; there was no significant association with body mass index. Conclusion: There is an association between some coping styles and quality of life in individuals who are candidates for bariatric surgery.
\end{abstract}

KEY WORDS: Obesity. Bariatric surgery. Psychological stress. Quality of life.

\section{Introduction}

Global obesity increase has become evident, as well as concerns to determine the causes of this phenomenon. World Health Organization figures indicate that, worldwide, one billion people have a body mass index (BMI) indicative of overweight (BMI of 25) and that at least 300 million suffer from obesity (BMI of 30), which is a risk factor for developing several health problems, including diabetes and hypertension. ${ }^{1-3} \mathrm{Ac}-$ cording to the Organization for Economic Cooperation and Development, the United States and Mexico show the highest prevalence of obesity in the world; $30 \%$ of the population in Mexico (34.5\% of adult women and $24.2 \%$ of men), which is equivalent to 36 million people. ${ }^{4}$ As a consequence, cases of type 2 diabetes, dyslipidemia and hypertension have increased in Mexico and it has been estimated that, in years to come, the increase in the burden of disease for the health system will almost double., ${ }^{4,5}$

Several genetic, psychological and social factors involved in the etiology of obesity and that affect the quality of life have been identified, including psychosocial stress. ${ }^{6,7}$ It has been reported that it can drive people to choose fat-rich and high energy density foods, as well as to show less willingness to prepare healthy foods and to perform physical and recreational activities, which can generate higher abdominal adiposity. ${ }^{6,8}$ Lower perception of stress is associated with higher quality of life in the mental health dimension of patients with obesity or overweight. ${ }^{7}$

In this sense, several studies have described that patients with obesity show higher vulnerability: they are the butt of jokes about their weight, their self-image is not favorable, they feel greater bodily pain, they consume lower quality food, their physical activity is scarce and they spend longer time in front of JV.,10
Correspondence:

Aída Monserrat Reséndiz-Barragán

E-mail: aidaresendiz@ hotmail.com
Date of reception: 30-01-2018

Date of acceptance: 18-07-2018

DOI://dx.doi.org/10.24875/GMM.M18000191
Gac Med Mex. 2018;154:482-486

Contents available at PubMed www.gacetamedicademexico.com 
The way patients with obesity approach different stressful situations is related to their coping style, which has been described as a process whereby constant cognitive and behavioral efforts are made to handle psychological stress generated by internal or external situations perceived as threatening or overwhelming; it is regarded as a tendency developed throughout life to use a method that enables coping with stressful situations. Generally, two major coping types can be recognized: action-directed and emotionally-oriented. ${ }^{11,12}$

In a study that evaluated coping styles of patients with morbid obesity, women were reported to show more passive and avoidant coping, which was associated with anger, as well as low confidence and no closeness in personal relationships. ${ }^{12}$ In another study, patients with morbid obesity who were bariatric surgery candidates were found not to effectively cope with problem-situations due to obesity stigmatization, which affects their self-esteem and self-concept, in addition to that avoidant coping is possibly related to a higher percentage of depression..$^{13}$ Similarly, patients who choose bariatric surgery as treatment have been reported to show a coping style of based on emotions rather than on an active dimension, which may be associates with higher distress and bad adaptive behaviors. ${ }^{12,14}$

While the association between stress and obesity, as well as the type of strategies for coping with stress and their effect on quality of life in individuals with overweight and obesity have been widely studied, there are only few investigations assessing these variables in bariatric surgery candidate population in Mexico, which leaves a great void in this area of knowledge, since Latin American population is prone to emotional coping associated with nutritional problems, overweight and obesity, ${ }^{15}$ which can negatively affect the results of bariatric surgery. ${ }^{14,16}$

Due to the above, the purpose of the present analysis was to identify and describe the association between the strategy for coping with stress, the perception of quality of life and the level of BMI in bariatric surgery candidates.

\section{Method}

Cross-sectional, observational, analytical study. Patients older than 18 years of age who were bariatric surgery candidates at Hospital General "Dr. Manuel Gea González" obesity clinic, with a BMI $\geq 40$ of 35 if they had comorbidities were included. Candidates for intragastric balloon and those who were on psychotherapeutic process were excluded. Those who did not answer all the questionnaires were censored.

The participants were recruited in the first-contact sessions at the hospital obesity and bariatric surgery clinic, which consisted of psycho-educational group talks of approximately 30 minutes, where they were provided general information about the procedures to be admitted to the clinic. Subsequently, three female psychologists from the clinic obtained written consent for participation in the investigation after providing information on the subject, distributed the questionnaires and the instructions required to fill them and provided assistance to solve any doubts; average time for this procedure was 45 minutes. Finally patient records were reviewed to obtain sociodemographic data, weight, height and BMI. The compilation of data was carried out between August 2015 and March 2016.

The Stress Coping Questionnaire ${ }^{17}$ was used in its version validated in Mexico. ${ }^{18}$ The instrument assessed seven coping forms grouped in two big factors:

\section{Emotional Coping}

- Open emotional expression: expressive manifestations towards other people about the negative emotional reaction related to the problem.

- Avoidance: thinking or doing other things ignoring the problem.

- Negative autofocusing: focusing on the negative aspects of oneself as responsible of the problem.

\section{Rational Coping}

- Search for social support.

- Religion.

- Focusing on problem solving: direct and rational action to solve problematic situations.

- Positive reassessment: creating a new positive meaning for the problem situation.

The answers were assessed in a Likert-type scale with a 0 to 4 range. The instrument is rated by adding the values marked $t$ each item for each subscale, with the predominant coping style being identified as the one with the highest score. The scale has reported good reliability levels in emotional coping (Cronbach's alpha of 0.71 ) and rational coping (Cronbach's alpha of 0.78 ).

The of Quality of Life and Health Inventory (InCaVi-Sa) ${ }^{19}$ evaluates the quality of life in patients with any chronic or acute condition with sensitivity to interventions. It is 
composed of 53 multiple-choice items with a Likert-type scale comprising answer options ranging from to never to always, which assess 11 areas of life, focusing on:

- Quality of life deterioration: concerns, isolation, body perception, cognitive functions, attitude towards treatment, spare time, daily life and medical dependence.

- Quality of life: physical performance, family, social networks and relationship with doctor.

- Perception of total quality of life.

Each item's scores are obtained by direct addition, where 0 is equal to never, 1 to almost never, 2 a few times, 3 often, 4 almost always and 5 always. The physical performance, family, social networks and relationship with doctor scales are scored backwards. The instrument shows internal consistency (alpha coefficients range from 0.6831 to 0.9337 ) and adequate concurrent validity.

$\mathrm{BMI}^{20}$ is the most widely used marker to identify obesity and overweight in adult population; it is obtained by dividing the weight in kilograms by squared height in meters. This way, a score is calculated that allows classifying in grade I obesity (30 to 34.9 points), grade II obesity (35 to 39.9 points) and grade III obesity (higher than 40 points).

The Kolmogorov-Smirnov test was applied to identify normality in the sample; since it was not found, using Spearman's correlation coefficient was decided in order to assess the association and strength between the strategy for coping with stress, the level of obesity and the perception of quality of life in patients who were bariatric surgery candidates. A p-value $\leq 0.05$ was considered to be statistically significant. To address the specific objective, a descriptive analysis was carried out, taking into account central and dispersion measures. The statistical program SPSS, version 15, was used for the analysis.

The study was approved by the Research and Ethics in Research Committee of the hospital where it was conducted, with registration number 46-14-2014.

\section{Results}

Hundred and twenty-seven patients were assessed, out of which 26 were excluded because they did not meet the inclusion criteria; the population was comprised by 101 patients, out of which $81.2 \%$ were of the female gender and $18.8 \%$ were males; age range was 17 to 70 years, with a mean of 38.92 (standard deviation $[\mathrm{SD}]=11.8$ years). Other sociodemographic data are described in table 1.
Table 1. Demographic characterization of bariatric surgery candidates

\begin{tabular}{lccccc|c}
\hline & Frequency & & Minimum & Maximum & Mean & SD \\
\hline Females & 82 & Age & 17 & 70 & 38.92 & 11.81 \\
Males & 19 & $\mathrm{~kg}$ & 62 & 220 & 113 & 29.05 \\
Total & 101 & $\mathrm{H}$ & 1.42 & 1.87 & 1.62 & 0.08 \\
& & $\mathrm{BMl}$ & 26.48 & 77.19 & 42.41 & 8.92 \\
\hline
\end{tabular}

$\mathrm{kg}=$ kilograms, $\mathrm{H}$ = height, $\mathrm{BMI}=$ body mass index, $\mathrm{SD}$ = standard deviation

With regard to coping strategies, the highest scores are focused on rational coping strategies: focusing on problem solution (average 14.21, range 4-24, SD 4.99), positive reassessment (average 13.37, range 4-23, SD 4.00), search for social support (average 11.38, range 0-24, SD 6.41) and religion (average 5.90, range $0-24$, SD 5.54). As for strategies based on emotional coping, the following values were obtained: open emotional expression (average 9.26, range 1-24, SD 5.54), avoidance (average 9.18, range 1-24, SD 4.32) and negative self-focusing (average 7.94, range 0-21, SD 4.26).

Regarding InCaViSa, the mean obtained indicated that patients had a good quality of life (average 111.50, SD 1.936). As regards the subscales that allow to identify the quality of life, a very high level was found in the family area (average 3.78, range 0-20, SD 3.939), high level in physical performance (average 10.06, range 2-18, SD 4.190), high level in social networks (average 7.55 , range $0-20$, SD 5,108) and in the relationship with doctors (average 10.29, range 0-20, SD 4.394). On the other hand, in the subscales of the instrument that indicate quality of life deterioration, a very high level of isolation was identified (average 5.55 , range $0-19, S D 4.471$ ) and in the attitude towards treatment (average 4.75, range 0-20, SD 3.640); high levels were found in concerns (average 9.54, range 0-20, SD 4.896), cognitive functions (average 7.56, range $0-18$, SD 4.092), spare time (average 9.52 , range $0-20$, SD 5.409), everyday life perception (average 9.06, range 0-20, SD 5.841) and medical dependence (average 7.50, range 1-20, SD 4.358). Finally, body perception was low (average 13.70, range 0-20, SD 4.747).

Of the four categories that compose rational coping, three had negative associations, and although weak, they were statistically significant: focusing on problem solving $\left(r_{s}=-0.2791, p=0.005\right)$, positive reassessment $\left(r_{s}=-0.211, p=0.034\right)$ and search for social support $\left(r_{s}=-0.249, p=0.012\right)$, with the exception of religion, the value of which was not statistically significant. As for the correlations obtained in emotional 
Table 2. Correlation between quality of life, strategies for coping with stress and body mass index in bariatric surgery candidates

BMI FPS NAF PRA OEE AVD SSS RLG

InCaVISa $0.145 \quad-0.2790 .461 \quad-0.2110 .3510 .023-0.249-0.058$

$\mathrm{p}$

$\begin{array}{llllllll}0.148 & 0.005 & 0.001 & 0.034 & 0.001 & 0.818 & 0.012 & 0.563\end{array}$

Statistically significant correlations are indicated in bold numbers. AVD = avoidance, BMI = body mass index, FPS = focusing on problem solving; InCaVISa=Quality of Life and Health Inventory, NSF = negative self-focusing, OEE = open emotional expression, $\mathrm{PRA}=$ positive reassessment, $\mathrm{RLG}=$ religion, $\mathrm{SSS}=$ search for social support.

Table 3. Body mass index correlation with strategies for coping with stress in bariatric surgery candidates

\begin{tabular}{lccccccc}
\hline & FPS & NAF & PRA & OEE & AVD & SSS & RLG \\
\hline BMI & -0.011 & 0.107 & 0.084 & 0.058 & 0.096 & 0.040 & -0.075 \\
p & 0.915 & 0.288 & 0.405 & 0.565 & 0.338 & 0.690 & 0.457
\end{tabular}

$\mathrm{AVD}=$ avoidance, $\mathrm{BMI}=$ body mass index, $\mathrm{FPS}$ = focusing on problem solving; $\mathrm{NSF}=$ negative self-focusing, $\mathrm{OEE}=$ open emotional expression, $\mathrm{PRA}=$ positive reassessment, $\mathrm{RLG}=$ religion, $\mathrm{SSS}=$ search for social support.

coping, two of the three categories showed weak, but statistically significant positive associations: open emotional expression $\left(r_{s}=0.351, p=0.001\right)$ and negative self-focusing $\left(r_{s}=0.461, p=0.001\right)$; no significant values were obtained for avoidance (Table 2). Finally, the seven coping types were correlated with $\mathrm{BMI}$, with no significant associations being obtained (Table 3).

\section{Discussion}

The present study had the purpose to identify the association between the strategy for coping with stress, the perception of quality of life and the level of BMI in patients who were candidates for bariatric surgery. Similarly, most common coping types and strategies in this population were described. According to the results, patients of this study showed coping strategies focused on action or the rational part (focusing on problem solving, positive reassessment and search for social support), which draws the attention since, according to the international literature, emotional coping predominates in this population. ${ }^{12-14} \mathrm{~A}$ possible explanation is what in clinical practice is observed: when questioning patients about their support network, most refer having at least one relative that provides significant support at moments of difficulty, mainly economic. Another possible reason is that participants answered the instruments with social desirability -they indicated that what they thought the researchers wanted to hear-, which could have generated the difference in results. There are investigations where the discrepancy between health information perceived by a population and laboratory results has been recorded. ${ }^{21}$

As regards quality of life, data show that the participants perceive a good quality of life, particularly in the family area, physical performance, social support networks and relationship with their treating physician; however, they recognize high deterioration in isolation (feelings of loneliness or separation from their usual group due to obesity), attitude towards medical treatments and concerns associated with obesity. The perception of high quality of life contrasts with reports in the international literature, since several studies mention that there is lower quality of life in patients with overweight and obesity, ${ }^{7}$ as well as in bariatric surgery candidates, and that the most affected areas are mobility, possibility carry out daily activities, pain, anxiety and depression. ${ }^{22}$

Various factors inherent to Latin American idiosyncrasy $^{23}$ might be influencing on the positive and optimistic form patients perceive the events related to their health status, even when they are suffering from critical illnesses, which would explain the differences in quality of life perception. ${ }^{24}$ In addition to what has been described, it is possible that participants responded the study instruments with social desirability. ${ }^{21}$

With regard to correlations, three coping styles focused on action (focusing on problem solving, positive reassessment and search for social support) were found to be negatively associated, although with a weak statistical significance, with quality of life deterioration, i.e. the more the focusing on solving problems, positive reassessment and search for social support, the less the deterioration in quality of life and vice versa. The obtained data are not uncommon, since several studies have reported that action-focused coping styles are often associated with more adaptive behaviors in situations of illness, and even lead to the search for information on different ailments, including cancer. ${ }^{25}$

Similarly, weakly significant positive correlations were obtained between two coping categories based on emotion (negative self-focusing and negative emotional reaction expression related to the problem) and quality of life deterioration. That is, the greater the negative self-focusing and negative emotional reaction expression related to the problem, the greater the deterioration in the perception of quality of life. These data are consistent with those reported in the international literature: patients with obesity who are candidates for bariatric surgery refer an emotionally-focused a coping style, and therefore they usually exhibit anger, depression, distress, personal relationships with poor 
confidence and bad adaptive behaviors, which ultimately diminish their quality of life. ${ }^{12-14}$

As previously noted, ${ }^{26}$ in the population with obesity, no significant relationships between BMI and coping styles were obtained, which apparently only have mediator effects on unhealthy emotions and behaviors., 1,10,12-14

As a limitation of the present investigation, the social desirability whereby patients answered the questionnaire was identified. ${ }^{21}$ In clinical practice, patients who are candidates for bariatric surgery manipulate the information because since the first contact they are informed that they will undergo an evaluation and preparation process that will determine whether or not they are candidates for surgery. This phenomenon hinders obtaining accurate information and complicates the proper identification and preparation of patients for bariatric surgery. In the future, it would be worth evaluating this phenomenon to determine the effect it has had on investigations in this population. In addition, the cross-sectional nature of this study prevents analyzing the coping styles used by patients at different moments of their lives and in different situations, which is relevant information considering that conditions can change depending on the existence of other variables. Similarly, more complex statistical analyses that could have provided more information about relationships between variables in order for causality to be established were not carried out. Finally, the present study was conducted in a single bariatric center of Mexico City, which does not allow generalizing its findings to the entire Mexican population.

Replicating this study in a multi-center trial, including other bariatric surgery clinics, using more complex statistical analyses and research lines that study social desirability in this population is recommended.

\section{References}

1. World Health Organization [sitio web]. Obesity and overweight. Contents available at: http://www.who.int/mediacentre/factsheets/fs311/en.

2. WHO Expert Consultation. Appropriate body-mass index for Asian populations and its implications for policy and intervention strategies. Lancet. 2004;363(9403):157-163.

3. Rahman MM, Akter S, Jung J, Rahman MS, Sultana P. Trend, projection, and appropriate body mass index cut-off point for diabetes and hypertension in Bangladesh. Diabetes Res Clin Pract. 2017;126:43-53.
4. Organización para la Cooperación y el Desarrollo Económicos. Obesity update 2012. Francia: Organización para la Cooperación y el Desarrollo Económicos; 2012.

5. Alegre-Díaz J, Herrington W, López-Cervantes M, Gnatiuc L, Ramírez R, Hill M, et al. Diabetes and cause-specific mortality in Mexico City. N Engl J Med. 2016;375(20):1961-1971.

6. Wardle J, Chida J, Gibson EL, Whitaker KL, Steptoe A. Stress and adiposity: a meta-analysis of longitudinal studies. Obesity (Silver Spring). 2011; 19(4):771-778.

7. Wang J, Sereika SM, Styn MA, Burke LE. Factors associated with health-related quality of life among overweight or obese adult. J Clin Nurs. 2013;22(15-16):2172-2182.

8. Adam T, Epel ES. Stress, eating and the reward system. Physiol Behav. 2007;91(4):449-458.

9. Buttitta M, lliescu C, Rousseau A, Guerrien A. Quality of life in overweight and obese children and adolescents: a literature review. Qual Life Res. 2014;23(4):1117-1139

10. Mouchacca J, Abbott GR, Ball K. Associations between psychological stress, eating, physical activity, sedentary behaviors and body weight among women: a longitudinal study. BMC Public Health. 2013;13:838.

11. Lazarus RS, Folkman S. Stress, appraisal, and coping. EE. UU.: Springer; 1984.

12. Hörchner R, Tuinebreijer WE, Kelder H, Van-Urk E. Coping behavior and loneliness among obese patients. Obes Surg. 2002;12(6):864-868.

13. Fettich KC, Chen EY. Coping and obesity stigma affects depressed mood in African-American and white candidates for bariatric surgery. Obesity (Silver Spring). 2012; 20(5):1118-1121.

14. Rydén A, Karlsson J, Persson LO, Sjöström L, Taft C, Sullivan M. Obesity-related coping and distress and relationship to treatment preference. Br J Clin Psychol. 2001;40(Pt 2):177-188.

15. Reyes-Rodríguez ML, Gulisano M, Silva Y, Pivarunas B, Luna-Reyes KL, Bulik CM. "Las penas con pan duelen menos": the role of food and culture in Latinas with disordered eating behaviors. Appetite. 2016;100:102-109.

16. Rydén A, Karlsson J, Sullivan M, Torgerson JS, Taft C. Coping and distress: what happens after intervention? A 2-year follow-up from the Swedish Obese Subjects (SOS) study. Psychosom Med. 2003;65(3): 435-442.

17. Sandín B, Chorot P. Cuestionario de Aprontamiento del Estrés (CAE): desarrollo y validación preliminar. Revista de Psicopatología y Psicología Clínica. 2003:6(1):39-54.

18. González M, Landero R. Cuestionario de Afrontamiento del Estrés (CAE): validación en una muestra mexicana. Revista de Psicopatología y Psicología Clínica. 2007:12(2):189-198.

19. Riveros-Rosas A, Sánchez-Sosa JJ, Del Águila M. Inventario de Calidad de Vida y Salud (InCaViSa). México: El Manual Moderno; 2009.

20. Regional office for Europe. Body Mass Index - BMI. World Health Organization; 2018. Contents available at: http://www.euro.who.int/en/health-topics/disease-prevention/nutrition/a-healthy-lifestyle/body-mass-index-bmi

21. Mossavar-Rahmani Y, Tinker LF, Huang Y, Neuhouser ML, McCann SE, Seguin RA, et al. Factors relating to eating style, social desirability, body image and eating meals at home increase the precision of calibration equations correcting self-report measures of diet using recovery biomarkers: findings from the Women's Health Initiative. Nutr J. 2013:12:63.

22. Twells LK, Driscoll S, Gregory DM, Lester K, Fardy JM, Pace D. Morbidity and health-related quality of life of patients accessing laparoscopic sleeve gastrectomy: a single-centre cross-sectional study in one province of Canada. BMC Obes. 2017:4:40.

23. Trapp SK, Perrin PB, Aggarwal R, Peralta SV, Stolfi ME, Morelli E, et al. Personal strengths and health related quality of life in dementia caregivers from Latin America. Behav Neurol. 2015;2015:507196.

24. Lavielle-Sotomayor P, Rozen-Fuller E, Bustamante-Rojano J, Martínez-Murillo C. Optimismo, cohesión familiar y tratamiento como predictores de la calidad de vida en padecimientos oncohematológicos. Rev Med Inst Mex Seguro Soc. 2017:55(4):456-463.

25. Saita E, Acquati C, Kayser K. Coping with early stage breast cancer: examining the influence of personality traits and interpersonal closeness. Front Psychol. 2015;6:88.

26. Kaymaz N, Düzçeker $Y$, Uzun ME, Aylanç $H$, Baştürk M, Yıldırım Ş. Influence of body mass index on mindfulness awareness and coping methods for stress in adolescents. Int J Adolesc Med Health. 2016;30(3):pii. 